\title{
The Past Victim, the Future Abuser
}

\author{
Ali Firoozabadi, $\mathrm{MD}^{1,2^{*}}$ \\ 'Research Center for Traditional Medicine and History of Medicine, Shiraz University of Medical Sciences, Shiraz, Iran \\ ${ }^{2}$ Associate Professor of Psychiatry, Hafez Hospital, Department of Psychiatry, Shiraz University of Medical Sciences, Shiraz, Iran
}

\begin{abstract}
Background: Childhood trauma exerts a significant effect on psychological life of people. It is a ubiquitous phenomenon. We face a social epidemic with serious consequences that shatter the life of survivors. Victimization in early years of life entraps the individuals in the victim-rescuer-abuser triangle. Many perpetrators and criminals have had history of childhood abuse. The main objective of this study was the assessment of patients with a history of child abuse who behaved in abusive manner in adulthood. Methods: By reviewing the files of 3694 patients referred to my outpatient private clinic, I tried to gather data to answer the questions related to this study including history of abuse, victimization, substance abuse, and the percent of patients who were involved in abusive behaviors in adulthood.

Results: In total, 1075 patients reported a history of some abuse during childhood (29.10\%). Of them, 19.44\% (total = 209, 78 men and 131 women) behaved as an abuser for most of their life. The prevalence of substance abuse in people with history of abuse was $36.6 \%$ compared to $28.36 \%$ in those without. The prevalence of acting as an abuser and perpetrator in adult life was $27.5 \%$, $19.5 \%, 18.4 \%$ and $11.11 \%$ among the divorced, married, single and widowed respectively.

Conclusion: This preliminary study showed that a significant number of patients with history of childhood abuse involved in abusive behavior and victimization of others in adulthood. Paying attention to this issue by mental health practitioners and policy makers can prevent the intergenerational transmission of abuse and development of a more peaceful society.

Keywords: Child abuse, Iran, Shiraz, Trauma, Victim

Cite this article as: Firoozabadi A. The past victim, the future abuser. Arch Iran Med. 2020;23(4 suppl 1):S6-S8. doi: 10.34172/ aim.2020.s2.
\end{abstract}

Received: February 25, 2019, Accepted: October 12, 2019, ePublished: April 1, 2020

\section{Introduction}

Trauma is a widespread and ubiquitous phenomenon in our world that affects people in different and diverse ways. People in some countries have been suffering from continuous turmoil and exhaustive conflicts. Physical and sexual abuse are constant parts of life in these areas. Also, trauma has not been rare in times of tranquility at all. A national survey, conducted by phone, of 2000 randomly selected individuals, aged 10-16, found that one half of the boys and one third of the girls had been subjected to some form of violent victimization. ${ }^{1}$ Russel found that the prevalence of sexual abuse in girls before the age of 18 was $38 \%$ and the prevalence of incest was $16 \% .^{2}$ As Howell mentioned, “... these rates might push expected normal personality structure into the realm of what one might call the pathological normal". ${ }^{3}$ Re-enactment of victimization is a major cause of violence. ${ }^{4}$ The association between childhood abuse and subsequent victimization of others has been found in many studies. ${ }^{5-9}$ Most child maltreatment occurs at home. About $80 \%$ of abusers are parents. ${ }^{9}$ Some people bear the heavy weight of their traumatic past on their shoulders. These experiences influence their behavior unconsciously. It seems that they have had no choice other than obeying the forces that channel them towards certain behaviors. The aim of such behaviors is to overcome the stresses of past trauma and rewrite early scenarios with a more tolerable ending. As a victim, children expect someone to come and help them. This rescuer may be a real person or represented by a fantasy figure in the victim's mind. Also, he/she cannot express his/her anger at the perpetrator. $\mathrm{He} /$ she is too weak to defend directly. Anger and hate accumulate in their mind and wait for appropriate time to be expressed. The triangular model introduced by Karpman ${ }^{10}$ can be applied to describe the behavior of such individuals who are trying to gain mastery over past traumatic experiences. However, without proper insight, such efforts are doomed to fail. They play the previous roles of victim, abuser (persecutor) and rescuer again and again in their life. Such behavior is expressed in several psychopathological conditions such as dissociative disorders, borderline personality, substance abuse disorders, mood disorders, eating disorders and somatic symptom disorders. In search for an environment capable of satisfying her/his needs, she/he involves in blind behaviors hoping to get a different result this time. Among these three roles, the role of persecutor (abuser) has a significant effect on reproduction of new abusers and continuation of victimization of people in the society. In this study, through the review of the past history of 3694 psychiatric outpatients, I tried to respond to this 
question: what percent of the patients who were victimized physically, sexually or neglected in the childhood, act as an abuser in adulthood? The triangle is not static and the role one plays is not fixed. However, I focused on the dominant role in the life history of each patient.

\section{Patients and Methods}

The electronic files of 3694 patients (2296 women and 1398 men) who referred to my private clinic in the last two years were reviewed. By abuser patient, I mean an individual who behaves predominantly as abuser in interpersonal relationships. Patients who acted periodically in the abuser role were excluded.

\section{Results}

Among the patients, 1075 reported a history of some abuse during childhood (29.10\%) (Table 1). Table 2 summarizes and shows the different types of abuse in the patients. The history of $19.44 \%$ of them (total $=209,78$ men and 131 women) indicated that they behaved as an abuser for most of their life. They were aggressive, bully, controlling, authoritative and superior in their relationships. Some of them had been involved in illegal acts and had history of substance abuse. The prevalence of substance abuse in the people with history of abuse was $36.6 \%$ compared to $28.36 \%$ in those without such a history. Table 3 shows the frequency of abuse among the divorced, married, single and widowed patients, which is $36.36 \%, 27.6 \%, 31.2 \%$ and $22.76 \%$, respectively. The prevalence of acting as an abuser and perpetrator in adult life among the divorced, married, single and widowed was $27.5 \%, 19.5 \%, 18.4 \%$

Table 1. Comparison of History of Child Abuse between Male and Female Patients

\begin{tabular}{lccc}
\hline Abuse History & Female & Male & Total \\
\hline Yes & $726(31.62 \%)$ & $349(24.97 \%)$ & $1075(29.10 \%)$ \\
No & $1570(68.37 \%)$ & $1049(75.03 \%)$ & $2619(70.90 \%)$ \\
Total & $2296(100 \%)$ & $1398(100 \%)$ & $3694(100 \%)$ \\
\hline
\end{tabular}

Table 2. Frequency of Different Types of Abuse

\begin{tabular}{lcc}
\hline Type of abuse & No. & Percent \\
\hline Physical/sexual & 46 & 4.30 \\
\hline Neglect & 345 & 32.11 \\
\hline Parental conflict & 301 & 28.00 \\
\hline Physical & 235 & 21.87 \\
Sexual & 148 & 13.72 \\
\hline Total & 1075 & 100 \\
\hline
\end{tabular}

and $11.11 \%$, respectively. In patients with history of abuse, $17.5 \%$ reported loss of one or two parents before the age of 11 , whereas the prevalence of parental loss before the age of 11 was $6.22 \%$ in the patients without history of abuse.

\section{Discussion}

This preliminary study shows that a remarkable number of patients with history of abuse in their childhood tend to behave as abusers in adulthood. As Miller mentioned, it seems that evil is re-produced in each new generation. She argues that the destructive behavior of people is the result of experience of cruelty at the beginning of their own life. She points out the life of a number of tyrants and authoritarian leaders such as Adolf Hitler, Milosevic and Stalin to show us the relationship between maltreatment in childhood and cruelty in adulthood. ${ }^{11}$ The concept of "repetition compulsion" was introduced by Freud and other psychoanalysts to describe the reenactment and persistent activation of early traumatic scenarios in the individual life. The ones who could not integrate the trauma repeat the repressed material as a current experience instead of remembering it as something belonging to the past. According to Janet, the traumatic memories persist as "fixed ideas" that act as foci for further repetition. ${ }^{12}$ Memories of trauma return as sensations, images, nightmares and behaviors, "as if their personality development has stopped at a certain point and cannot expand anymore by the addition or assimilation of new elements" ${ }^{12}$ Freud believed that the goal of repetition was to gain mastery over the trauma but as Van der Kolk noted, this rarely happens and repetition causes further suffering. ${ }^{4}$

A considerable finding in this study was the dominance of female patients among the patients who acted as abusers in adult life $(62.7 \%$ women vs. $37.3 \%$ men). Carmen et al ${ }^{13}$ indicate that through the mechanism of "identification with aggressor", boys victimize others whereas abused women would be attached to an abusive man. This contemplation is not supported by our study. However, we have to wait for more sophisticated studies to obtain a reliable conclusion.

We found higher rates of victimization and also acting as abusers in the history of divorced individuals. It can be a measure indicating the importance of a history of trauma in marital life and its fate.

Repetition of the past trauma in the form of abusive behavior leads to continuation of victimization. The past

Table 3. Marital Status in Patients with and without History of Abuse

\begin{tabular}{|c|c|c|c|c|c|}
\hline Abuse History & Divorced & Married & Single & Widowed & Total \\
\hline Yes & $121(63.68 \%)$ & $1436(72.93 \%)$ & $1001(68.75 \%)$ & $61(77.22 \%)$ & $2619(70.90 \%)$ \\
\hline No & $69(36.32 \%)$ & $533(27.07 \%)$ & $455(31.25 \%)$ & $18(22.78 \%)$ & $1075(29.10 \%)$ \\
\hline Total & $190(100 \%)$ & 1969 (100\%) & $1456(100 \%)$ & $79(100 \%)$ & $3694(100 \%)$ \\
\hline
\end{tabular}


victim becomes the future abuser and this pattern repeats itself in the next generation. The goal of treatment is to help such patients to gain control over their life rather than repeating trauma in action. ${ }^{4}$ A peaceful society could be established by peaceful and adapted individuals. People who are in peace with themselves can develop peaceful relationships with others in the external world. The current victim is a potential persecutor in the future. Appropriate and timely interventions have a significant role in preventing such undesirable consequences and reappearance of another Hitler.

This is a preliminary study that shed a dim light on an important subject. Further and more sophisticated studies should be done to address many unanswered questions about the interactions among factors which influence the destiny of children in their life. As Chu mentioned, abuse is often accompanied by a sense of shame and the children may be reluctant to reveal what happened. A caring and warm environment could help the children to recruit their inner resiliency to overcome the consequences of trauma.

\section{Limitations}

This is a study on patients referring to a single private clinic which reduces external validity. The method of identification of "abuser" and "abused" has been based on clinical judgment in routine psychiatric interviews. Since the study has been based on secondary data and noting the limited time allocated to examining such a high number of patients without a clear-cut method and instrument, the possibility of identifying the "abused" is higher than having been an "abuser" with no history of being abused and this might have led to a systematic error. This is a preliminary study and the author hopes to design more elaborated studies in the future to shed light on such an important issue.

Authors' Contribution

Gathering of data, statistical analysis and the writing of manuscript all have accomplished by the author.

\section{Conflict of Interest Disclosures}

None.

\section{Ethical Statement}

Ethical issue of this study has been approved by ethics committee of Archives of Iranian Medicine.

\section{References}

1. Boney-McCoy S, Finkenlhor D. Is your victimization related to trauma symptoms and depression after controlling for prior symptoms and family relationships? A longitudinal. Prospective study. J Consult Clin Psychol. 1996;64:1406-16.

2. Russell D. The Secret Trauma: Incest in the Lives of Girls and Women. New York: Basic Books. 1986.

3. Howell EF. The Dissociative Mind. New York: Routledge Taylor \& Francis Group; 2005

4. Van der Kolk BA. The compulsion to repeat the trauma. Psychiatr Clin North Am. 1989;12(2):389-411.

5. Krystal H. Trauma and affect. Psychoanal Study Child. 1978;33:81-116. doi: 10.1080/00797308.1978.11822973

6. Lewis DO, Pincus JH, Bard B, Richardson E, Prichep LS, Feldman $M$, et al. Neuropsychiatric, psychoeducational and family characteristics of 14 juveniles condemned to death in the United States. m J Psychiatry. 1988;145(5):584-9. Doi: 10.1176/ajp.145.5.584

7. Lewis DO, Shanok SS, Pincus JH, Glaser GH. Violent juvenile delinquents. Psychiatric, neurological, psychological and abuse factors. J Am Acad Child Psychiatry. 1979;18(2):307-19.

8. Seghorn TK, Prentky RA, Boucher RJ. Childhood sexual abuse in the lives of sexually aggressive offenders. J Am Acad Child Adolesc Psychiatry. 1987;26(2):262-7.

9. Chu JA. Rebuilding Shattered Lives: Treating Complex PTSD and Dissociative Disorders. 2nd ed. Hoboken, NJ: John Wiley \& Sons, Inc. 2011.

10. Karpman S. Fairy tales and script drama analysis. Transactional Analysis Bulletin. 1968;7(26):39-43.

11. Miller A. The Truth will Set You Free: Overcoming Emotional Blindness and Finding your True Adult Self. Translated by Andrew Jenkins. New York: Basic Books; 2001.

12. Janet P. The Mental State of Hystericals. Paris: Félix Alcan; 1911.

13. Carmen EH, Reiker PP, Mills T. Victims of violence and psychiatric illness. Am J Psychiatry. 1984;141(3):378-83. 